\title{
Role and responsibility of the speciality futor
}

\section{Comparison between two regions in old age psychiatry and suggestions for the future}

\author{
Jane Garner and Yong Lock Ong
}

\begin{abstract}
Aims and method In order to identify the role and responsibility of the speciality tutor, the tutors' post in old age psychiatry was compared across two regions. Results The role was narrow; but different in the two regions depending on training programmes. Clinical implications Tutors in all faculties should have an expanded and standardised job description, separate from the role of the regional representative, in order to strengthen the input of the specialisms to training at all levels.
\end{abstract}

In this post-Calman era, with firm but commendable emphasis being placed on quality and quantity of postgraduate education and training, it seems timely to examine the role of the speciality tutor and increase the tutor's profile. Currently regional representatives, not tutors, are asked for feedback, both to the faculty executive and to the business meeting. Although the speciality tutor is to have an overview of training locally, regional represenatives (on behalf of the regional adviser) comment on new consultant job descriptions assessing whether the post will be too onerous to preclude training of juniors. Job descriptions for specialist registrars are sent to speciality advisory committees to obtain educational approval. The speciality tutor is not involved in these procedures.

The role of the college tutor is well established (Tutors' Sub-Committee, 1993) with guidelines describing the responsibilities and terms of reference. In comparison the role and duties of the speciality tutor have not been clearly defined. The College description of the speciality tutor (Education Committee, 1989) as having responsibility for the organisation of training in that speciality for a particular region fails to take into account local differences in the organisation of training; the number of higher training rotations usually depends on the number of academic departments in that region.

There are on the College list of tutors (February, 1997) 110 speciality tutors: 17 psychotherapy: 24 learning disabilities; 26 child and adolescent; four addictions; 13 forensic; 15 old age; one research; and 10 who do not have their specialities defined.

A letter sent by us to other Royal Colleges in August 1997 drew two interesting responses. There are speciality regional advisers in pathology whose main responsibilities are to provide support for the regional adviser in postgraduate education and to advise on local matters. The Royal College of Physicians has created associate tutors from among their trainees which provides an early involvement with College activities.

\section{Old age psychiatry}

The role of the speciality tutor varies tremendously from region to region, as illustrated by the differences in North-East Thames and East Anglian regions. North Thames (East) has four separate specialist registrar training schemes in general and old age psychiatry, based on the four teaching hospitals; the Royal Free Hospital, The University College London Hospital, St Bartholomew's Hospital and the Royal London Hospital. The structure, administration and organisation of these schemes is the responsibility of the programme directors. All four schemes include training opportunities in old age psychiatry, some on a separate but a linked rotation, others as part of a general and old age psychiatry scheme.

Within this organisational system, the role of the speciality tutor has been an informal one seeing trainees who intend to specialise in old age psychiatry, discussing training requirements and opportunities and supporting those who are experiencing uncertainties or difficulties in their training. The tutor invites all trainees to the regional meetings of old age psychiatrists. These meetings have an academic component as well as providing an opportunity for specialist registrars to meet with peers and senior colleagues to discuss issues of mutual concern and to share clinical and other work experiences.

The East Anglian scheme in general and old age psychiatry provides a single rotation 
incorporating all posts within East Anglia. Appointments are made to the scheme as a whole rather than to individual hospitals. The 17 posts provide wide experience and training in general psychiatry and its sub-specialities with two years spent in Cambridge and one or two years in other districts: Huntingdon. Bury St Edmunds, Norwich, King's Lynn, Ipswich, Peterborough and St Andrews Hospital, Northampton. As there is a single programme director the speciality tutor is involved in organisational tasks: establishing an educational plan and Certificate of Completion of Specialist Training (CCST) dates for trainees; allocating posts and in addition ensuring a third of the posts is assigned to old age. There is a similar pastoral role in underpinning the activities of speciality tutors in both regions.

The North Thames (East) tutor sits on the regional education committee, a forum for discussing senior house officer training and on the Speciality Training Committee held at the Deanery. Both are chaired by the regional adviser. The Speciality Training Committee comprises the specialist registrar scheme organisers, speciality tutors, deputy regional advisers and postgraduate deans. Meetings are lively events and were particularly so during the Calman transition period out of which old age psychiatry secured further manpower slots due to the numbers of eligible juniors wishing to train for a career in old age psychiatry. The tutor is now part of the Record of In-Training Assessment panel at the Deanery. As expected there are parallel committee commitments in East Anglia.

\section{The future}

\section{For old age psychiatry}

The Dean and Sub-Deans of the Royal College have discussed the role of the speciality tutor (Minutes of College Education Committee, 3 June 1997) and agreed that this needs some clarification. The existing document The Role and Responsibility of Specialty Tutors in Old Age Psychiatry prepared some years ago by John Wattis (further details available from the author upon request) is being rewritten by the old age faculty executive. Good training is essential for the continuing development of old age psychiatry. The speciality tutor should be promoting this at all levels. the new job description should give the speciality tutor greater influence at senior house officer level, including deciding whether an old age post is suitable for a senior house officer with no previous experience in general psychiatry. Perhaps the tutor could have an overview of and input to the content of MRCPsych courses having regards to College curricula and speciality reading lists. Each region now has a deputy regional adviser whose remit is continuing professional development, and the speciality tutor should be available to discuss with this adviser matters relating to old age psychiatry. It would be helpful if the speciality tutor were to have a knowledge of potential research resources within the region.

The tutor will need to advise the postgraduate dean(s) on training needs and College requirements. Speciality tutor applications are routinely referred to the regional adviser so that the tutor should have their support. Regional speciality tutors and regional speciality representatives need to have good channels of communication, both between themselves and with the local body of consultants responsible for their nomination. The tutor and representative should be the voice of the faculty and old age psychiatry as a whole in the region.

Faculty manpower calculations indicate the need for $\mathbf{1 0 0}$ more specialist registrar posts in old age psychiatry. The outcome of the Speciality Workforce Advisory Group's (SWAG) annual review: Old Age Psychiatry 1998/99 (further details available from the author upon request) indicated that 20 more posts (revised to 10) may be created but these are at the expense of general psychiatry. Speciality tutors may need to be part of the lobbying for more posts regionally and nationally at senior house officer and specialist registrar grades. The good schemes have no difficulty recruiting at specialist registrar level with the great majority of old age trainees opting for a joint CCST with general psychiatry. General training in old age psychiatry is now well organised and recognised by most trainees as providing the necessary experience and knowledge base to equip them for consultant posts. The four years for a dual CCST should be long enough for trainees to develop a special interest within old age psychiatry and perhaps this subspecialisation could be encouraged by tutors to the benefit of trainees and their profession in general.

\section{For all faculties}

Most speciality tutors will welcome a clarification of their role with an expanded and redrafted job description as it will result in strengthening their input for the benefit of the specialisms. Recommended guidelines would create some standardisation of practice while allowing for the development of regional differences according to local schemes.

Over the past few years concern has been expressed that general psychiatry is losing out to specialities in training and recruitment. Many reasons have been suggested for this loss of attraction (Deahl \& Turner, 1997). One way to 
address some of the issues would be to have a speciality tutor in general psychiatry to raise the profile for generalists, regionally and with the College.

\section{Caveat}

A suggestion has been made to combine the role of regional representative with that of speciality tutor. This was raised at the Executive and Finance Committee in December 1997 and has been taken back to faculties for comment. It has stimulated a robust debate. In our opinion it would be a shame to lose the close working relationships between representative and tutor which often gives rise to a broader spectrum of views. Although there may be some logical coherence in joining the two tasks, this amalgamation is likely to be too burdensome for a single person. particularly if our suggestions for the extended responsibilities of the tutor are accepted.

\section{References}

DEAHL, M. \& TURNER, T. (1997) General psychiatry in noman's land. British Journal of Psychiatry, 171, 6-8.

EDUCATION COMMrTTEE (1989) Recognition of Psychiatric Tutors and Others Concerned with the Provision of Postgraduate Psychiatric Education and Training. London: Royal College of Psychiatrists.

Tutors Sub-COMmrTte (1993) Role of the College Psychiatric Tutor.

Jane Garner, Regional Advisor, North East Thames (previously Regional Speciality Tutor) and *Yong Lock Ong, Regional Speciality Tutor, Old Age Psychiatry, North East Thames (previously Goodmayes Hospital, Barley Lane. Goodmayes, Essex IG3 8YB)

*Correspondence

\section{How to pass the MRCPsych examination}

\section{Cormac and G. Marston}

Membership of the Royal College of Psychiatrists is the main qualification needed to progress from the basic training grade (senior house officer) to higher professional training (specialist registrar) in psychiatry. The Collegiate Trainees Committee (CTC) recognises that the MRCPsych examinations may generate anxiety in candidates and require a large investment in time and personal resources. The examinations are competitive, with approximately $50 \%$ of candidates passing on each attempt. It is worthwhile preparing well the first time, by planning in advance and understanding the critical factors for success. This article aims to help trainees preparing for the MRCPsych examination.

\section{Information from the College}

Trainees should obtain the current examination curricula, regulations and information about applications soon after they commence training. by writing to the Examinations Department at the College (see Appendix).

Both parts of the examination are held in the autumn and the spring. Part I selects those candidates suitable for progression to further basic training. It comprises a multiple choice question paper (MCQ) and a clinical examination, based on a patient interview. Part I may be taken after 12 months of full-time training or the equivalent in part-time training. Unlimited attempts at the MCQ are allowed and only successful candidates proceed to the clinical examination. A maximum of four attempts are allowed at the clinical examination.

Part II is more demanding, exploring knowledge in greater breadth and depth to select candidates suitable for higher specialist training. At least 30 months psychiatric experience is required, including up to six months in another approved speciality. The examination comprises two multiple choice question papers, one on clinical subjects and one on basic sciences. The 